\title{
Optimization of perforation distribution for horizontal wells based on genetic algorithms
}

\author{
Wang Zhiming ${ }^{1 *}$, Wei Jianguang ${ }^{1}$, Zhang Jian ${ }^{1,2}$, Gong Bin ${ }^{3}$ and Yan Haiyun ${ }^{1}$ \\ ${ }^{1}$ School of Petroleum Engineering, China University of Petroleum, Beijing 102249, China \\ ${ }^{2}$ China United Coalbed Methane Co., Ltd., Beijing 100011, China \\ ${ }^{3}$ Faculty of Engineering, Peking University, Beijing 100084, China \\ (C) China University of Petroleum (Beijing) and Springer-Verlag Berlin Heidelberg 2010
}

\begin{abstract}
Early water breakthrough and a rapid increase in water cut are always observed in highpermeability completion intervals when perforations are uniformly distributed in the wellbore in heterogeneous reservoirs. Optimization of perforating parameters in partitioned sections in horizontal intervals helps homogenize the inflow from the reservoir and thus is critically important for enhanced oil recovery. This paper derives a coupled reservoir-wellbore flow model based on inflow controlling theory. Genetic algorithms are applied to solving the model as they excel in obtaining the global optimum of discrete functions. The optimized perforating strategy applies a low perforation density in highpermeability intervals and a high perforation density in low-permeability intervals. As a result, the inflow profile is homogenized and idealized.
\end{abstract}

Key words: Well completion, perforation optimization, genetic algorithms, partition, horizontal well

\section{Introduction}

In the conventional completions for horizontal wells, perforations are uniformly distributed along the horizontal wellbores. Permeability heterogeneity along a horizontal wellbore will cause a high rate of fluid inflow from the reservoir into the wellbore in high-permeability intervals, thus an early water breakthrough will occur in these intervals. On the other hand, the pressure drop shows a high value at the heel of horizontal wellbores (Dikken, 1990; Sarica et al, 1994). This also leads to a higher inflow rate at the heel and an earlier water breakthrough.

In 1991, by modeling perforations as finite, Landman and Goldthorp (1991) established a perforation optimization model for horizontal wells and analyzed the perforation distribution when the fluid flow from the reservoir to the well is uniform. However, they did not take into account the effect of formation damage and crushed zone damage. In 1993, taking into consideration the formation damage, perforating damage, well inclination, and deposit boundary, Marett and Landman (1993) established an optimization model of perforating parameters for horizontal wells by introducing the perforation skin factor into the coupled model. Their model is capable of computing perforation density in presence of wellbore inclination and permeability heterogeneity. In

*Corresponding author. email: wangzm@cup.edu.cn, wellcompletion@126.com

Received November 18, 2008
1997, Asheim and Oudeman classified the flowing pressure drop into three parts - inflow pressure drop, perforation pressure drop, and wellbore pressure drop. They modeled the perforations as microwellbores. In consequence, penetration length, diameter, and spacing are modeled as well length, diameter, and drainage radius, respectively. By calculating every flowing pressure drop, an analytical model of perforation optimization for horizontal wells was established based on pressure continuity. The optimal distribution of perforation density along the wellbore and the effect of optimized perforation on the horizontal well flow efficiency were analyzed. Zhou et al $(2001 ; 2002 ; 2007)$ studied the perforation density along the wellbore using the same method as Asheim and Oudeman. Wang et al (2005) studied the optimization of perforation distribution for horizontal wells in homogeneous reservoirs. Wang et al (2007) studied the effect of perforation distribution on inflow profiles in horizontal wells. Their research illustrated that the completion parameters are the main factors influencing inflow profiles in horizontal wells. However, permeability heterogeneity along the wellbore was not considered and optimization of perforating parameters in each partitioned segments has not been conducted according to the distribution of permeability along a horizontal wellbore. In these studies, perforation distribution along the wellbore was only qualitatively analyzed, and engineering practices have not been well implemented in order to provide realistic boundary conditions for perforation optimization. 


\section{Coupled model of wellbore and heteroge- neous reservoir flow}

As shown in Fig. 1, the inflow profile will be non-uniform because the permeability is different along a horizontal well. An idea of optimization of perforating parameters for a horizontal well is to partition the horizontal wellbore into a number of sections and optimize the perforating parameters in each section according to flow resistance in the reservoir and wellbore. As a result, the inflow profile of each section is optimized to be as close as possible to an ideal inflow profile which is only valid for infinite-conductivity, homogeneous reservoirs.

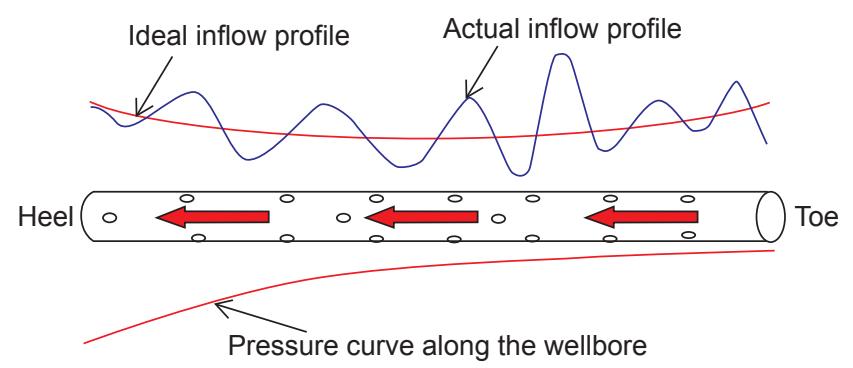

Fig. 1 Inflow profiles along a horizontal well

\subsection{Reservoir flow model}

The following assumptions are necessary to the flow model:

1) Only a single-phase incompressible Newtonian fluid is involved;

2) Isothermal condition;

3) The reservoir is of uniform thickness;

4) The reservoir formation far away from the wellbore is homogeneous, and its permeability is the average reservoir permeability;

5) The permeability is uniform in each section along the wellbore.

As shown in Fig. 2, the horizontal well is divided into $N$ sections, each with length of $\Delta L$ and well inclination of $\theta$. The distance between each section and the reservoir bottom is $z_{\mathrm{w}, j}$. For uniform inflow from the reservoir into the wellbore under pseudo steady-state conditions, each section can be looked upon as a vertical well, and the equivalent radius of each vertical well section is:

$$
\begin{aligned}
r_{\text {wew }, i}= & \Delta L \exp \left(-0.75+\frac{h}{\Delta L} \sqrt{\frac{K_{\mathrm{h}}}{K_{\mathrm{v}}}} \times\right. \\
& \ln \left[\frac{\pi r_{\mathrm{w}}}{h}\left(1+\sqrt{\frac{K_{\mathrm{v}}}{K_{\mathrm{h}}}}\right) \sin \frac{\pi z_{\mathrm{w}, i}}{h}\right]+ \\
& \left.\frac{2 h^{2}}{\Delta L^{2}} \frac{K_{\mathrm{h}}}{K_{\mathrm{v}}}\left(\frac{1}{3}-\frac{z_{\mathrm{w}, i}}{h}+\frac{z_{\mathrm{w}, i}^{2}}{h^{2}}\right)-\frac{h}{\Delta L} \sqrt{\frac{K_{\mathrm{h}}}{K_{\mathrm{v}}}} S_{\mathrm{t}, i}\right)
\end{aligned}
$$

where $r_{\text {wew }, i}$ is the equivalent radius of section $i, \mathrm{~m} ; \Delta L$ is the section length, $\mathrm{m} ; h$ is the reservoir thickness, $\mathrm{m} ; r_{\mathrm{w}}$ is the radius of the horizontal wellbore, $\mathrm{m} ; z_{\mathrm{w}, i}$ is the distance between section $i$ and the bottom of the reservoir formation, $\mathrm{m} ; K_{\mathrm{h}}$ is the horizontal permeability, $10^{-3} \mu \mathrm{m}^{2} ; K_{\mathrm{v}}$ is the vertical permeability, $10^{-3} \mu \mathrm{m}^{2} ; S_{\mathrm{t}, i}$ is the total skin of section $i$, dimensionless.

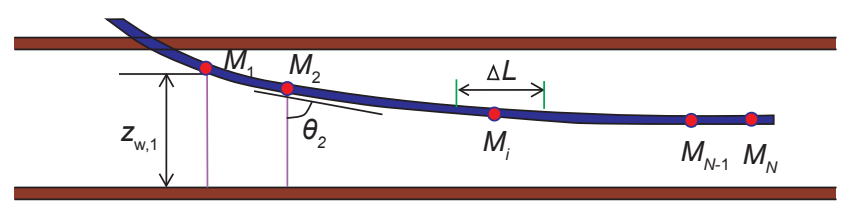

Fig. 2 Cross-sectional geometric parameters for a conventional horizontal well

As shown in Fig. 3, based on the superposition principle, the potential at an arbitrary point is expressed as follows:

$$
\Phi_{M}=\frac{1}{0.54287} \sum_{i=1}^{N} q_{i} \ln r_{i}+C
$$

Taking positions on the supply boundary and wellbore of each equivalent vertical well, the relationship between bottom-hole pressure and flow rate at different positions of horizontal wells can be derived as:

$$
\begin{aligned}
& p_{\mathrm{e}}-p_{\mathrm{wfwr}, i}=\frac{\mu}{0.54287 h K_{\mathrm{h}}} \sum_{n=1}^{N} \Delta L q_{\mathrm{ws}, n} \ln \left(\frac{r_{\mathrm{e}}}{r_{\mathrm{w} n, \mathrm{w} i}}\right) \\
& r_{\mathrm{w} n, \mathrm{w} i}= \begin{cases}\sqrt{\left(x_{n}-x_{i}\right)^{2}+\left(y_{n}-y_{i}\right)^{2}} & (i \neq n) \\
r_{\mathrm{wew}, i} & (i=n)\end{cases}
\end{aligned}
$$

where $\mu$ is the fluid viscosity, $\mathrm{mPa} \cdot \mathrm{s} ; p_{\mathrm{e}}$ is the reservoir boundary pressure, MPa; $r_{\mathrm{e}}$ is the supply radius, $\mathrm{m} ; p_{\mathrm{wfwr}, i}$ is the pressure at the wall of section $i, \mathrm{MPa} ; q_{\mathrm{ws}, i}$ is the inflow rate of section $i, \mathrm{~m}^{3} /(\mathrm{s} \cdot \mathrm{m}) ; r_{\mathrm{w} n, \mathrm{w} i}$ is the distance from the centre of section $n$ to the center of section $i, \mathrm{~m} ; x_{i}$ and $y_{i}$ are the coordinates of the center of section $i, \mathrm{~m}$.

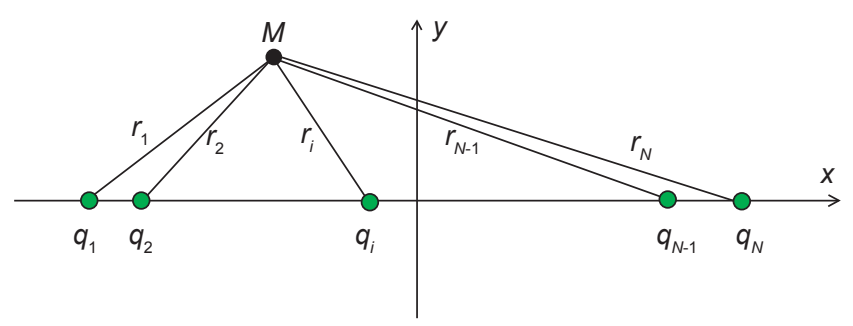

Fig. 3 Potential superposition principle for well sections

\subsection{Near wellbore flow model}

The total resistance to flow from the reservoir to the heel of the horizontal well consists of the resistance to flow in the reservoir far away from the wellbore, the inflow resistance nearby and through the well, and the complicated flow resistance in the wellbore (Fig. 4).

As a result of permeability heterogeneity at different positions along the wellbore, the inflow rate is different along the horizontal well. This will speed up the inflow in high-permeability regions and slow down the inflow in lowpermeability regions. The inflow profile is thus fluctuating along the whole wellbore. In order to investigate the influence of permeability heterogeneity on horizontal well inflow 


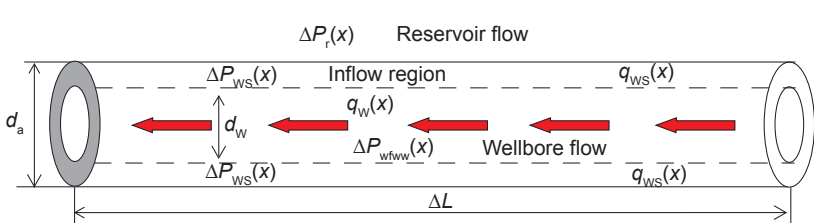

Fig. 4 Near-wellbore flow

profiles and the optimization result of completion parameters, the equivalent diameter or investigation diameter in the heterogeneous region is assumed to be $d_{\mathrm{a}}$. According to the definition of the skin factor, the heterogeneous model of the pseudo skin factor near the wellbore can be defined as:

$$
S_{\mathrm{a}}\left(x_{i}\right)=\left[\frac{K}{K_{\mathrm{a}}\left(x_{i}\right)}-1\right] \ln \left(\frac{d_{\mathrm{a}}}{d_{\mathrm{w}}}\right)
$$

The total skin of each infinitesimal well section can be represented as:

$$
S_{\mathrm{t}}\left(x_{i}\right)=S_{\mathrm{p}}\left(x_{i}\right)+S_{\mathrm{a}}\left(x_{i}\right)
$$

where $K_{\mathrm{a}}\left(x_{i}\right)$ is the average permeability of infinitesimal well section $i, 10^{-3} \mu^{2} ; K$ is the average permeability along the whole wellbore, $10^{-3} \mu \mathrm{m}^{2} ; d_{\mathrm{a}}$ is the diameter of the region exhibiting permeability heterogeneity, $\mathrm{m} ; d_{\mathrm{w}}$ is the well diameter, $\mathrm{m} ; S_{\mathrm{t}}\left(x_{i}\right)$ is the total skin of infinitesimal well section $i$, dimensionless; $S_{\mathrm{p}}\left(x_{i}\right)$ is the perforation skin factor of infinitesimal well section $i$, dimensionless, calculated from the model proposed by Furui (2004); $S_{\mathrm{a}}\left(x_{i}\right)$ is the pseudo skin factor of well infinitesimal section $i$, dimensionless.

\subsection{Wellbore flow model}

The pressure drop across section $i$ in the horizontal wellbore is derived according to the conservation of momentum and mass. It is the sum of acceleration pressure drop, friction pressure drop, and gravity pressure drop:

$$
p_{\mathrm{wfww}, i}-p_{\mathrm{wfww}, i-1}=\Delta p_{\mathrm{acc}, i}+\Delta p_{\mathrm{wall}, i}+\Delta p_{\mathrm{g}, i}
$$

The acceleration pressure drop can be expressed as:

$\Delta p_{\mathrm{acc}, i}=\frac{32 \rho q_{\mathrm{ws}, i}}{\pi^{2} d_{\mathrm{w}}^{4}} q_{\mathrm{w}, i} \cdot \Delta L$

The friction pressure drop can be expressed as:

$\Delta p_{\text {wall }, i}=\frac{32 \rho f_{\mathrm{t}, i}}{\pi^{2} d_{\mathrm{w}}^{5}} q_{\mathrm{w}, i}^{2} \cdot \Delta L$

The gravity pressure drop can be expressed as:

$\Delta p_{\mathrm{g}, i}=\rho g \cos \theta_{i} \cdot \Delta L$

Substituting Eq. (7) into Eq. (6) gives:

$$
\begin{aligned}
& p_{\mathrm{wfww}, i}-p_{\mathrm{wfww}, i-1} \\
& =\left(\frac{32 \rho q_{\mathrm{ws}, i}}{\pi^{2} d_{\mathrm{w}}^{4}} q_{\mathrm{w}, i}+\frac{32 \rho f_{\mathrm{t}, i}}{\pi^{2} d_{\mathrm{w}}^{5}} q_{\mathrm{w}, i}^{2}+\rho g \cos \theta_{i}\right) \Delta L
\end{aligned}
$$

The cross-sectional flow rate is:

$$
q_{\mathrm{w}, i}=\sum_{j=i}^{N}\left(q_{\mathrm{ws}, j} \Delta L\right)
$$

where $p_{\mathrm{wfww}, i}$ is the wellbore pressure in the center of infinitesimal well section $i, \mathrm{MPa} ; \Delta p_{\mathrm{acc}, i}$ is the acceleration pressure drop in infinitesimal section $i, \mathrm{MPa} ; \Delta p_{\text {wall }, i}$ is the friction pressure drop in infinitesimal section $i, \mathrm{MPa} ; \Delta p_{\mathrm{g}, i}$ is the gravity pressure drop in infinitesimal section $i, \mathrm{MPa} ; q_{\mathrm{w}, i}$ is the cross-sectional flow rate of infinitesimal section $i, \mathrm{~m}^{3} / \mathrm{s}$; $f_{\mathrm{t}, i}$ is the total variable mass inflow friction coefficient of infinitesimal section $i$, dimensionless, calculated from the model proposed by Ouyang et al (1996); $\theta_{i}$ is the deviation angle of infinitesimal section $i$, degrees.

\subsection{Derivation of coupled flow model}

At any point on the well wall, the reservoir fluid pressure is equal to the wellbore fluid pressure. This natural boundary condition yields:

$$
P_{\mathrm{wfww}, i}=p_{\mathrm{wfwr}, i}
$$

When the well produces at a constant bottom-hole flowing pressure, the boundary condition is:

$$
p_{\mathrm{wfww}, 0}=p_{\mathrm{wf}}
$$

Combining Eq. (3) with Eq. (10) gives

$$
A_{1} X_{1}=b_{1}
$$

Combining Eq. (8) with Eq. (11) gives:

$$
A_{2} X_{2}=b_{2}
$$

with

$$
X_{1}=\left[\begin{array}{llll}
q_{\mathrm{ws}, 1} & q_{\mathrm{ws}, 2} & \cdots & q_{\mathrm{ws}, N}
\end{array}\right]^{\mathrm{T}}
$$$$
X_{2}=\left[\begin{array}{llll}
p_{\text {wfww }, 1} & p_{\text {wfww }, 2} & \cdots & p_{\text {wfww }, N}
\end{array}\right]^{\mathrm{T}}
$$$$
a_{n, i}=\frac{\mu \Delta L}{0.54287 h K_{\mathrm{h}}} \ln \left(\frac{r_{\mathrm{e}}}{r_{\mathrm{w} n, \mathrm{w} i}}\right)
$$$$
b_{1}=\left[\begin{array}{c}
p_{\mathrm{e}}-p_{\mathrm{wfww}, 1} \\
p_{\mathrm{e}}-p_{\mathrm{wfww}, 2} \\
\vdots \\
p_{\mathrm{e}}-p_{\mathrm{wfww}, N-1} \\
p_{\mathrm{e}}-p_{\mathrm{wfww}, N}
\end{array}\right]
$$

$$
b_{2}=\left[\begin{array}{c}
\left(\frac{32 \rho q_{\mathrm{ws}, 1}}{\pi^{2} d_{\mathrm{w}}^{4}} q_{\mathrm{w}, 1}+\frac{32 \rho f_{\mathrm{t}, 1}}{\pi^{2} d_{\mathrm{w}}^{5}} q_{\mathrm{w}, 1}^{2}+\rho g \cos \theta_{1}\right) \Delta L+p_{\mathrm{wf}} \\
\left(\frac{32 \rho q_{\mathrm{ws}, 2}}{\pi^{2} d_{\mathrm{w}}^{4}} q_{\mathrm{w}, 2}+\frac{32 \rho f_{\mathrm{t}, 2}}{\pi^{2} d_{\mathrm{w}}^{5}} q_{\mathrm{w}, 2}^{2}+\rho g \cos \theta_{2}\right) \Delta L \\
\vdots \\
\left(\begin{array}{c}
\frac{32 \rho q_{\mathrm{ws}, N-1}}{\pi^{2} d_{\mathrm{w}}^{4}} q_{\mathrm{w}, N-1}+\frac{32 \rho f_{\mathrm{t}, N-1}}{\pi^{2} d_{\mathrm{w}}^{5}} q_{\mathrm{w}, N-1}^{2}+\rho g \cos \theta_{N-1}
\end{array}\right) \Delta L \\
\left(\frac{32 \rho q_{\mathrm{ws}, N}}{\pi^{2} d_{\mathrm{w}}^{4}} q_{\mathrm{w}, N}+\frac{32 \rho f_{\mathrm{t}, N}}{\pi^{2} d_{\mathrm{w}}^{5}} q_{\mathrm{w}, N}^{2}+\rho g \cos \theta_{N}\right) \Delta L
\end{array}\right]
$$




$$
A_{1}=\left[\begin{array}{ccc}
a_{1,1} & \cdots & a_{N, 1} \\
a_{1,2} & \cdots & a_{N, 2} \\
\vdots & & \vdots \\
a_{1, N-1} & \cdots & a_{N, N-1} \\
a_{1, N} & \cdots & a_{N, N}
\end{array}\right]
$$

$$
A_{2}=\left(\begin{array}{cccc}
1 & 0 & \cdots & 0 \\
-1 & \ddots & \ddots & \vdots \\
\vdots & \ddots & \ddots & 0 \\
0 & \cdots & -1 & 1
\end{array}\right)
$$

\section{Optimization of perforating parameters}

\subsection{Optimization procedure}

The optimization procedure for perforating parameters in each section is given as below:

1) According to the permeability along the wellbore in heterogeneous reservoirs, the permeability function $K(x)$ is developed with the interpolation and then the average permeability $K$ is calculated.

2) Ideal inflow rates $q_{\mathrm{id}}\left(x_{1}\right), q_{\mathrm{id}}\left(x_{2}\right), \cdots, q_{\mathrm{id}}\left(x_{n}\right)$ are calculated from the model which couples horizontal wellbore flow with inflow from the heterogeneous reservoir into the wellbore under the condition of homogeneous permeability $K$ in an infinite-conductivity reservoir.

3) Ideal skin factors $S_{\mathrm{id}}\left(x_{1}\right), S_{\mathrm{id}}\left(x_{2}\right), \cdots, S_{\mathrm{id}}\left(x_{n}\right)$ are calculated from the coupled model under the condition of homogeneous permeability $K$ in an infinite-conductivity reservoir.

4) According to permeability function $K(x)$, heterogeneous model of total skin factor, and the inflow profile velocity control theory, the perforating parameters should satisfy $\min \left|S_{\mathrm{id}}(x)-S_{\mathrm{t}}(x)\right|$ as much as possible.

5) According to the actual field limitations and specifications, the optimization of perforating parameters in each section is achieved using genetic algorithms.

\subsection{Application of genetic algorithms}

\subsubsection{Encoding of the perforating parameters}

The optimization of perforating parameters for each section in a horizontal well is to minimize $\left|S_{\text {id }}(x)-S_{\mathrm{t}}(x)\right|$ under some constraints. The perforating parameters include the bullet type, perforation density, perforation phasing, and perforation location. The binary code is selected as shown in Fig. 5. The solution space, i.e., the length of binary code string can be changed to balance the accuracy and efficiency.

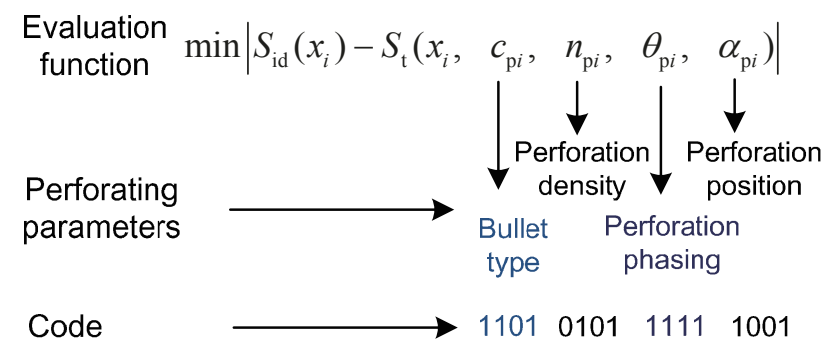

Fig. 5 Binary code of perforating parameters

\subsubsection{Determination of the fitness function}

The fitness of individuals is evaluated using the objective function, $\min \left|S_{\mathrm{id}}(x)-S_{\mathrm{t}}(x)\right|$. The evaluation function can be given by expressing the total skin as a function of coordinates and perforating parameters:

$$
\min \left|S_{\mathrm{id}}\left(x_{i}\right)-S_{\mathrm{t}}\left(x_{i}, c_{\mathrm{p} i}, n_{\mathrm{p} i}, \theta_{\mathrm{p} i}, \alpha_{\mathrm{p} i}\right)\right|
$$

where $c_{\mathrm{p} i}$ is the bullet type, dimensionless; $n_{\mathrm{p} i}$ is the perforation density, $\mathrm{m}^{-1} ; \theta_{\mathrm{p} i}$ is the perforation phasing, degrees; $\alpha_{\mathrm{p} i}$ is the perforation azimuth, degrees.

Constraints for optimization of perforating parameters for each section in the horizontal well include: (1) maximum/ minimum perforation density values exist for each type of perforating bullet, (2) the allowed range of phase angle, and (3) optimized parameters should be integers, such as bullet type, perforation density, perforating phasing, and perforation position.

\section{Computational examples}

\subsection{Parameters}

Table 1 summarizes the input parameters in the example. Permeability values along the horizontal well are shown in Table 2. Four cases, with different permeability distributions, are modeled respectively, and the average permeability of each case is $250 \mathrm{mD}$. The diameter of the heterogeneous

\begin{tabular}{|c|c|c|c|}
\hline Supply radius, $\mathrm{m}$ & 500.0 & Oil viscosity, $\mathrm{mPa} \cdot \mathrm{s}$ & 5.0 \\
\hline Reservoir thickness, $\mathrm{m}$ & 10.0 & $\begin{array}{c}\text { Oil formation volume } \\
\text { factor }\end{array}$ & 1.15 \\
\hline $\begin{array}{l}\text { Distance between } \\
\text { the wellbore to the } \\
\text { formation bottom, m }\end{array}$ & 5.0 & Degree of damage & 0.4 \\
\hline Outer casing diameter, $\mathrm{m}$ & 0.1397 & Damaged depth, m & 0.12 \\
\hline Casing wall thickness, $\mathrm{m}$ & 0.00917 & Fluid density, $\mathrm{kg} / \mathrm{m}^{3}$ & 950 \\
\hline $\begin{array}{c}\text { Relative roughness } \\
\text { of casing wall }\end{array}$ & 0.1 & Liquid production, $\mathrm{m}^{3} / \mathrm{d}$ & 200 \\
\hline Well length, m & 400.0 & Perforating gun & $102-102$ \\
\hline $\begin{array}{l}\text { Maximum perforation } \\
\text { density, shots } / \mathrm{m}\end{array}$ & 16 & $\begin{array}{c}\text { Number of partitioned } \\
\text { sections }\end{array}$ & 20 \\
\hline Perforation length, m & 0.525 & \begin{tabular}{|c|}
$\begin{array}{c}\text { Crushed zone } \\
\text { thickness, } \mathrm{m}\end{array}$ \\
\end{tabular} & 0.002 \\
\hline Perforation diameter, $\mathrm{m}$ & 0.011 & $\begin{array}{c}\text { Crushed zone } \\
\text { permeability, } 10^{-3} \mu \mathrm{m}^{2}\end{array}$ & 10.0 \\
\hline
\end{tabular}
region is three times the well diameter.

Table 1 Values of related parameters

\subsection{Interpretation of results}

In order to study the effect of permeability heterogeneity along the horizontal well on the optimization of perforating parameters, optimized perforating parameters were analyzed for four cases. In these cases, only the optimization of perforation density was carried out to equalize the specific inflow into each section of twenty 20 -meter well sections. The optimized perforation density values for each section are listed in Table 3. The optimized perforation density in each 
Table 2 Permeability values along the horizontal well

\begin{tabular}{|c|c|c|c|c|}
\hline \multirow{2}{*}{$\begin{array}{l}\text { Distance to the toe of } \\
\text { the horizontal well, } m\end{array}$} & \multicolumn{4}{|c|}{ Permeability, $10^{-3} \mu \mathrm{m}^{2}$} \\
\hline & Case 1 & Case 2 & Case 3 & Case 4 \\
\hline 0 & 150 & 100 & 203 & 250 \\
\hline 10 & 117 & 252 & 258 & 250 \\
\hline 30 & 156 & 119 & 200 & 250 \\
\hline 50 & 338 & 231 & 281 & 250 \\
\hline 70 & 53 & 104 & 296 & 250 \\
\hline 90 & 185 & 359 & 261 & 250 \\
\hline 110 & 500 & 131 & 241 & 250 \\
\hline 130 & 398 & 235 & 243 & 250 \\
\hline 150 & 194 & 381 & 295 & 250 \\
\hline 170 & 205 & 252 & 292 & 250 \\
\hline 190 & 13 & 372 & 212 & 250 \\
\hline 210 & 317 & 316 & 241 & 250 \\
\hline 230 & 31 & 228 & 210 & 250 \\
\hline 250 & 144 & 247 & 240 & 250 \\
\hline 270 & 340 & 242 & 247 & 250 \\
\hline 290 & 387 & 206 & 264 & 250 \\
\hline 310 & 99 & 175 & 282 & 250 \\
\hline 330 & 243 & 347 & 247 & 250 \\
\hline 350 & 94 & 215 & 216 & 250 \\
\hline 370 & 278 & 257 & 209 & 250 \\
\hline 390 & 452 & 300 & 240 & 250 \\
\hline 400 & 450 & 300 & 230 & 250 \\
\hline $\begin{array}{c}\text { Ratio of maximum to average } \\
\text { permeabilities } \\
\end{array}$ & 2.0 & 1.5 & 1.2 & 1 \\
\hline $\begin{array}{c}\text { Ratio of maximum to minimum } \\
\text { permeabilities }\end{array}$ & 38.0 & 4.0 & 1.5 & 1 \\
\hline
\end{tabular}

section is different along the horizontal well. The perforation density is low in high-permeability regions and high in lowpermeability regions.

The inflow characteristics of the modified and conventional completions are plotted in Figs. 6 and 7. For the uniformly perforated case, the specific inflow rate changes severely as the permeability heterogeneity increases (see Fig. 6). For the optimized perforated case, the specific inflow rate from high permeability regions reduces and the specific inflow rate from low permeability regions increases. The inflow profile from the reservoir to the wellbore is close to ideal, thus delaying water breakthrough and avoiding a rapid increase in water cut.

Comparisons of pressure drops, as shown in Fig. 7, indicate the pressure drop fluctuation is more noticeable along the horizontal well with more heterogeneity. However, the variation in perforation density has little influence on pressure
Table 3 Optimized perforation density along the horizontal well

\begin{tabular}{|c|c|c|c|c|}
\hline \multirow{2}{*}{$\begin{array}{l}\text { Distance to } \\
\text { the toe of the } \\
\text { horizontal well, } m\end{array}$} & \multicolumn{4}{|c|}{ Optimized perforation density, shots/m } \\
\hline & Case 1 & Case 2 & Case 3 & Case 4 \\
\hline $0-20$ & 16 & 14 & 13 & 16 \\
\hline $20-40$ & 16 & 16 & 16 & 16 \\
\hline $40-60$ & 7 & 16 & 11 & 16 \\
\hline $60-80$ & 16 & 16 & 10 & 16 \\
\hline $80-100$ & 16 & 7 & 13 & 16 \\
\hline $100-120$ & 5 & 16 & 16 & 16 \\
\hline $120-140$ & 6 & 16 & 16 & 16 \\
\hline $140-160$ & 16 & 7 & 10 & 16 \\
\hline $160-180$ & 16 & 14 & 10 & 16 \\
\hline $180-200$ & 16 & 7 & 16 & 16 \\
\hline $200-220$ & 8 & 8 & 16 & 16 \\
\hline $220-240$ & 16 & 16 & 16 & 16 \\
\hline $240-260$ & 16 & 15 & 16 & 16 \\
\hline $260-280$ & 7 & 16 & 15 & 16 \\
\hline $280-300$ & 6 & 16 & 12 & 16 \\
\hline $300-320$ & 16 & 16 & 10 & 15 \\
\hline $320-340$ & 13 & 7 & 15 & 15 \\
\hline $340-360$ & 16 & 16 & 16 & 15 \\
\hline $360-380$ & 9 & 13 & 16 & 15 \\
\hline $380-400$ & 5 & 9 & 16 & 15 \\
\hline
\end{tabular}

Notes: Perforating gun: 102-102; Penetrating charge: DP44RDX-1

drop across the entire horizontal well, i.e. the pressure drop along the entire horizontal well almost remains the same after optimization.

Table 4 shows that the productivity index of the well reduces slightly after the perforation density is optimized in each section in the horizontal well, and the reduction in the productivity index is more obvious as the level of permeability heterogeneity is greater.

Table 4 A comparison of productivity indexes before and after perforation optimization

\begin{tabular}{|c|c|c|c|c|}
\hline \multirow{2}{*}{ Case } & \multicolumn{2}{|c|}{$\begin{array}{c}\text { Productivity index } \\
\mathrm{m}^{3} /(\mathrm{d} \cdot \mathrm{MPa})\end{array}$} & \multirow{2}{*}{$\begin{array}{l}\text { Reduction in } \\
\text { productivity } \\
\text { index } \\
\mathrm{m}^{3} /(\mathrm{d} \cdot \mathrm{MPa})\end{array}$} & \multirow{2}{*}{$\begin{array}{l}\text { Loss ratio of } \\
\text { productivity } \\
\text { index } \\
\%\end{array}$} \\
\hline & $\begin{array}{c}\text { Before } \\
\text { optimization }\end{array}$ & $\begin{array}{c}\text { After } \\
\text { optimization }\end{array}$ & & \\
\hline Case 1 & 60.34 & 57.56 & 2.78 & 4.60 \\
\hline Case 2 & 63.00 & 62.02 & 0.98 & 1.55 \\
\hline Case 3 & 63.40 & 63.00 & 0.40 & 0.63 \\
\hline Case 4 & 64.63 & 64.42 & 0.21 & 0.32 \\
\hline
\end{tabular}




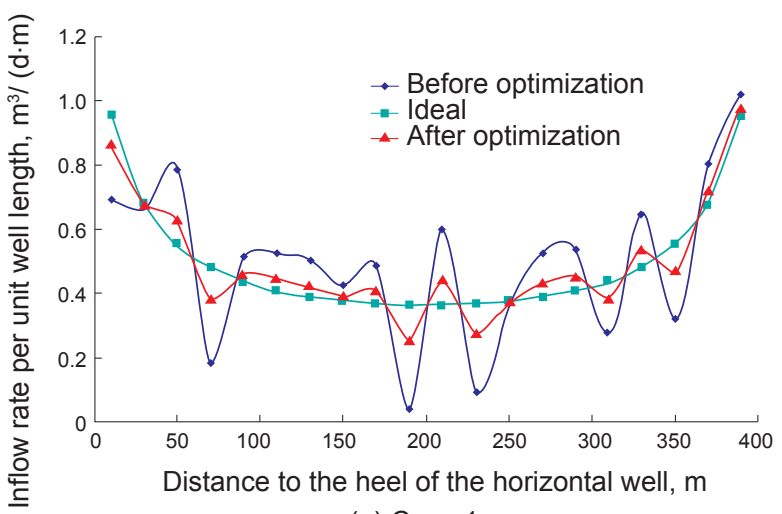

(a) Case 1

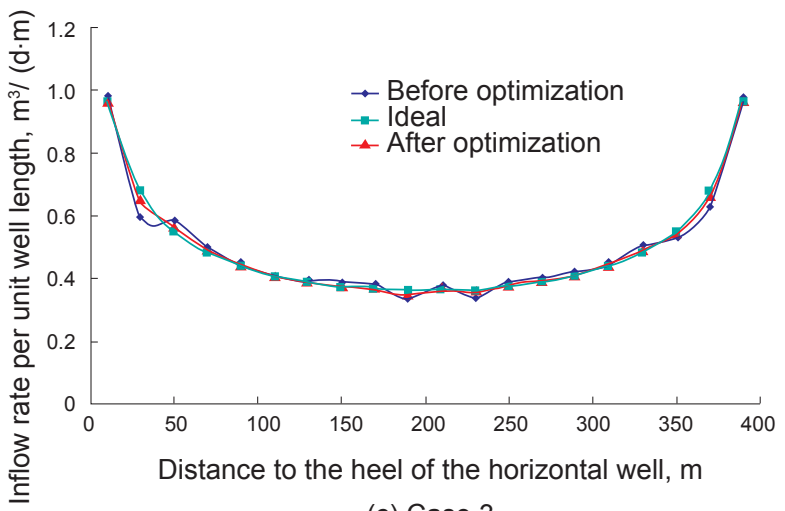

(c) Case 3

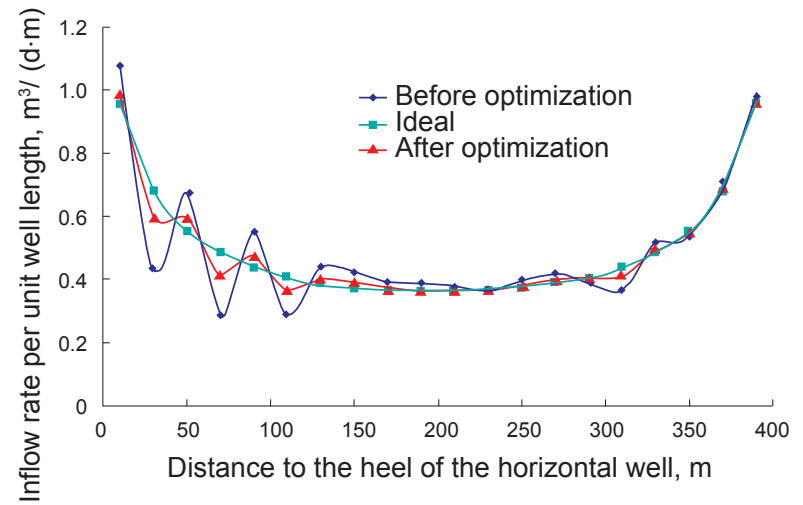

(b) Case 2

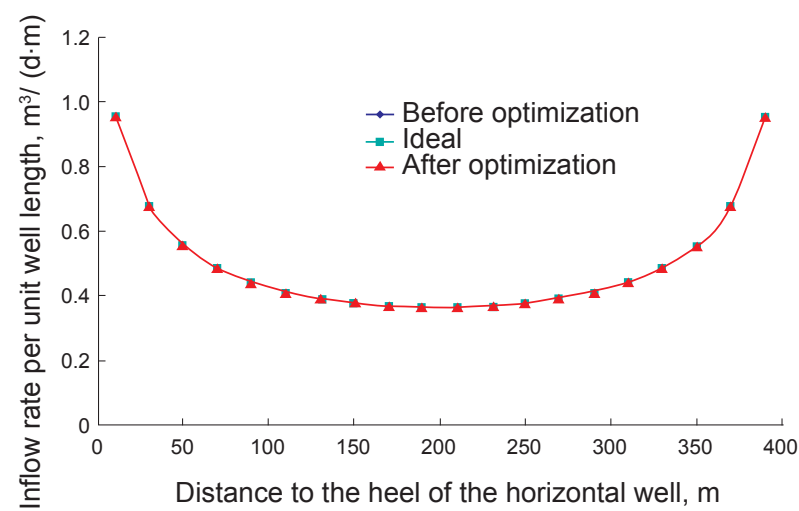

(d) Case 4

Fig. 6 Optimization of the perforation density to achieve a more uniform specific inflow

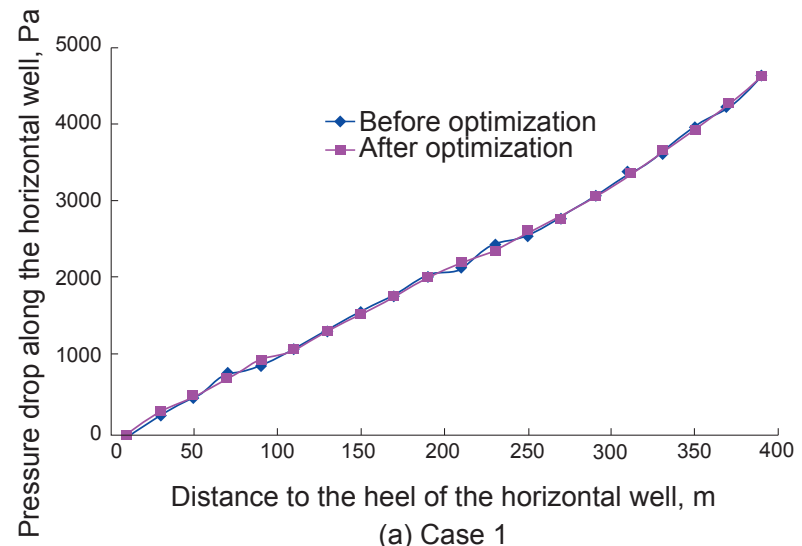

(a) Case 1

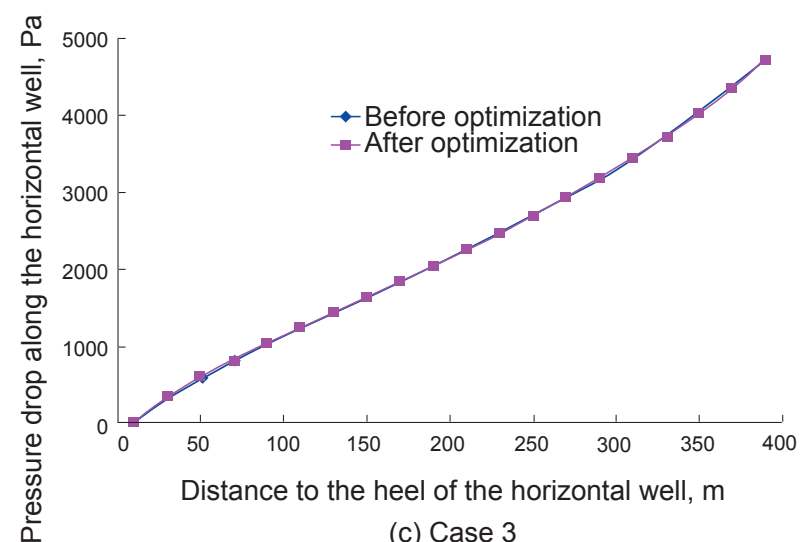

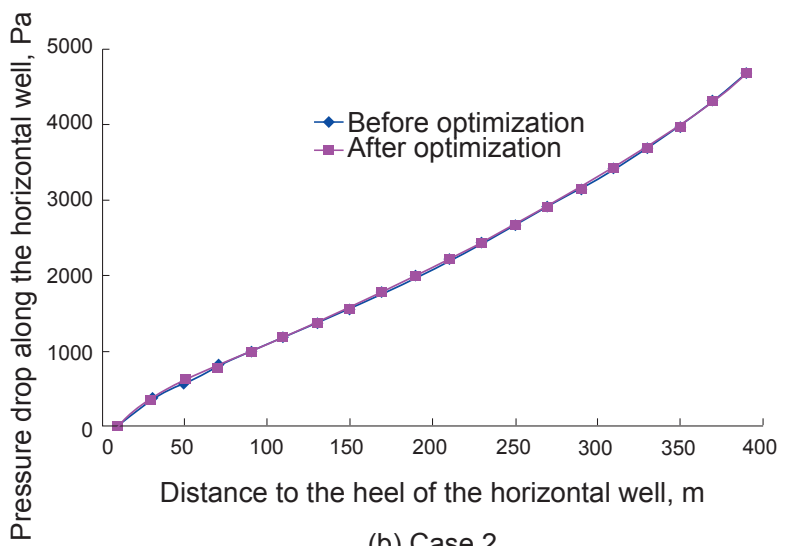

(b) Case 2

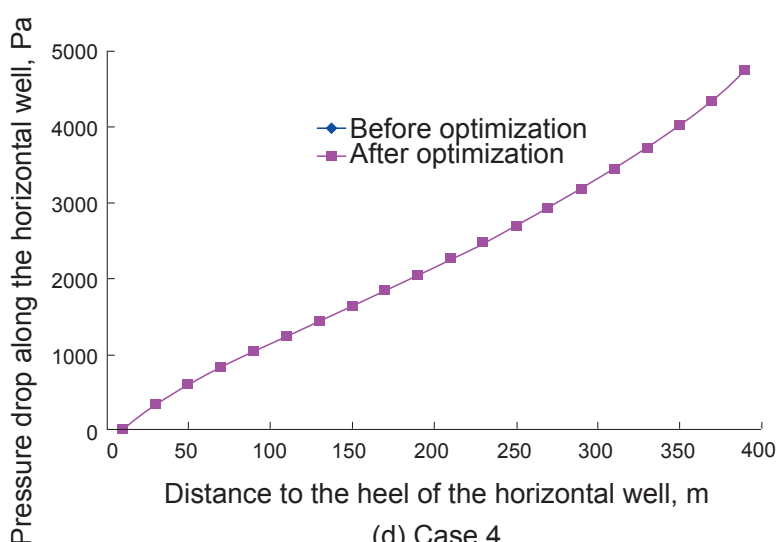

Fig. 7 Comparison of pressure drops before and after optimization of the perforation density 
In general, the optimization of perforation distribution in each section does not have a significant effect on the productivity index of the horizontal well.

\section{Conclusions}

1) A model is developed which incorporates horizontal wellbore flow with flow from the heterogeneous reservoir. The optimization of perforation density is achieved using genetic algorithms.

2) Before optimization of the perforation distribution for each section in the horizontal well, the inflow rate fluctuates severely as the reservoir permeability changes sharply. After optimization of perforation distribution in each section, the inflow from high permeability regions reduces and the inflow from low permeability regions improves. Therefore, the inflow from the reservoir to the wellbore is close to ideal, thus reducing the risk of premature water breakthrough and avoiding a rapid increase in water cut.

3) Perforation distribution is not uniform from the toe to the heel of the horizontal well. The perforation density is low in high-permeability regions and high in lowpermeability regions. The productivity index reduces slightly after perforation distribution is optimized in each section of the horizontal well and the reduction in productivity index is slightly more obvious as the level of permeability heterogeneity is greater. Generally speaking, the optimization of perforation distribution for horizontal wells does not have a significant effect on the productivity index.

\section{Acknowledgements}

This research is supported by National Scientific Project (No. 2008ZX05024-03).

\section{References}

Asheim H and Oudeman P. Determination of perforation schemes to control production and injection profiles along horizontal wells. SPE
Drilling \& Completion. 1997. 12(1): 13-18 (Paper SPE 29275)

Dikken B J. Pressure drop in horizontal wells and its effect on production performance. Journal of Petroleum Technology. 1990. 11: 1426-1433

Furui K. A Comprehensive Skin Factor Model for Well Completions Based on Finite Element Simulations. Ph.D Thesis. The University of Texas at Austin. 2004

Landman M J and Goldthorpe W H. Optimization of perforation distribution for horizontal wells. Paper SPE 23005 presented at SPE Asia-Pacific Conference, 4-7 November 1991, Perth, Australia

Marett B P and Landman M J. Optimization of perforation distribution for horizontal wells in reservoirs with boundaries. Paper SPE 25366 presented at SPE Asia Pacific Oil and Gas Conference, 8-10 February 1993, Singapore

Ouyang L B, Arbabi S and Aziz K. General wellbore flow model for horizontal, vertical, and slanted well completions. Paper SPE 36608 presented at the 1996 SPE Annual Technical Conference and Exhibition, 6-9 October 1996, Denver; also published at SPE Journal. 1998. 3(2): 124-133

Sarica C, Haciislamoglu M, Raghavan R, et al. Influence of wellbore hydraulics on pressure behavior and productivity of horizontal gas wells. Paper SPE 28486 presented at SPE Annual Technical Conference and Exhibition, 25-28 September 1994, New Orleans, Louisiana

Wang S P, Li Z P, Luo Y, et al. Analysis of perforation tunnel distribution mode in horizontal wells. Drilling \& Production Technology. 2007. 30(2): 39-41 (in Chinese)

Wang Z M, Xu J, Wang X Q, et al. Study of variable density perforating model of two-phase flow in horizontal wells. Journal of the University of Petroleum, China. 2005. 29(3): 65-69 (in Chinese)

Zhou S T and Su X Y. Specific properties of horizontal wellbores and optimal analysis of the perforation density. Journal of the University of Petroleum, China. 2001. 25(6): 55-57 (in Chinese)

Zhou S T, Ma D Q and Liu M. Optimization of perforation tunnel distribution in perforated horizontal wells. Journal of the University of Petroleum, China. 2002. 26(3): 52-54 (in Chinese)

Zhou S T. Analysis of perforation density optimization in perforated horizontal wells. Petroleum Drilling Techniques. 2007. 25(5): 55-57 (in Chinese)

(Edited by Sun Yanhua) 